\title{
National Health Insurance Scheme: Internal and External Barriers in the Use of Reproductive Health Services among Women
}

\author{
Evi Martha $^{1 *}$, Herna Lestari², Resvi Siti Zulfa1, Yoslien Sopamena ${ }^{1}$
}

\begin{abstract}
1Department of Health Education and Behavioral Science, Faculty of Public Health, Universitas Indonesia, Depok, Indonesia
${ }^{2}$ Yayasan Kesehatan Perempuan, South Jakarta, Jakarta, Indonesia
\end{abstract}

\begin{abstract}
Lack of familiarity among the community, medical workers, and administrative staff regarding reproductive health services covered by Badan Penyelenggara Jaminan Sosial (BPJS) or the National Health Insurance (NHI) in Indonesia remained a problem. Therefore, this resulted in sub-optimal use of the medical services, as shown by surveys from the Women's Health Foundation for three consecutive years (2015-2017). This qualitative study was conducted with a Rapid Assessment Procedure design in three cities within Indonesia: Padang Pariaman, Manado, and Kupang. Data were collected through IDIs ( $n=47$ informants) and 6 FGDs (7 persons/group). Participants also consisted of NHI RHS users (mothers and young women), administrative officers at health facilities, medical services providers, and officials related to the $\mathrm{NHI}$ assistance. Data were managed using NVivo version 2.0 software, accompanied by thematic analysis. The internal barriers in NHI use included inadequate knowledge of RHS covered by NHI, and a culture of shame in informants. External barriers included additional costs for medicines not covered by $\mathrm{NHI}$, the dissatisfaction of health services provided by medical workers, busy work and household activities, and lack of women's role in decision-making within families, which related to reproductive wellness.
\end{abstract}

Keywords: National Health Insurance, reproductive health, the Social Security Administrative Body for Health, women

\section{Introduction}

The International Conference on Population and Development (ICPD) in Cairo (1994), which set out a bold call-to-action on Sexual and Reproductive Health and Rights (SRHR), affirmed that choice and selfdetermination, gender equality, and human rights constitute the keystone of population policies. ${ }^{1-3}$ The goals of Sustainable Development Goals (SDGs) are to ensure healthy lives and promote the well-being of all at all ages (SDG 3), in order to achieve gender equality and women's empowerment (SDG 5), which signifies the increased access toward SRH services, ensure their affordability, and advance sex evenness. ${ }^{4}$

Health is one of the basic needs of every individual regardless of their gender. Access to complete sexual and reproductive health services (RHSs) was crucial to the well-being of individuals, families, and communities. ${ }^{5}$ Global efforts to improve women's health are largely focused on improving their reproductive wellness. ${ }^{6,7}$ Since 2014, the Government of the Republic of Indonesia had organized a National Health Insurance (NHI)

Correspondence*: Evi Martha, Department of Health Education and Behavioral Science, Faculty of Public Health, Universitas Indonesia, D Building 1st Floor Kampus Baru UI Depok 16424, Indonesia, E-mail: evimartha@yahoo.com, Phone: +62 8174883103 program, administered by the Social Security Administrative Body for Health, to ensure the fulfillment of basic medical needs, including RHSs. Expectations were that by 2019 , all Indonesian citizens are likely to become NHI participants.

Reproductive health services in primary health care had numerous benefits. ${ }^{8}$ A study conducted on 39 women in India demonstrated that participants were receptive to the availability of RHSs in primary care and the benefits of streamlining it, provided clinicians approach these services in a manner that respects patient autonomy and reproductive desires. ${ }^{8}$ In other study, RHSs at private hospitals that enrolled in the NHI scheme of India were $2 \%$. Over $75 \%$ of respondents were unaware of RHSs availability, through NHI. It was possible for respondents with some education to have this knowledge, while poorer families were less likely to be aware. ${ }^{9}$ Improvements in using existing public resources were also important for efficiency, quality, and equity gains. ${ }^{4}$

Based on a survey by the Women's Health Foundation 
in 15 provinces within Indonesia in 2015 - 2017, the use of RHSs by the community was not optimal. The utilization of services was mostly carried out for antenatal care $(24.5 \%)$ and normal delivery $(31.7 \%)$. Moreover, with clinical and administrative officers, the community was not fully aware about the types of women's RHSs being covered by the NHI. The Women's Health Foundation study also showed that most respondents knew that RHSs were limited to antenatal care, normal delivery, complications, and family planning services. ${ }^{6}$ However, there were numerous reproductive services provided by NHI, such as general screening, post-natal service, breast and cervical cancer analysis, and more.

This qualitative study aimed to explore the in-depth reasons for the low utilization of the NHI scheme for women's RHSs, in three regions of Indonesia. The results were expected to be used as advocacy material to the relevant government, to make policies and increase RHSs usage covered by NHI.

\section{Method}

This study was conducted after ethical approval was obtained from the Institutional Review Board at the University of Indonesia, with the numbers LB.02.01/2/KE.296/2018. Study participants were required to sign the informed consent form. Before seeking their consent, participants were also assured that their personal information was to be kept confidential when the study results are published. This qualitative study was conducted in three areas, represented by specific regions within Indonesia. The Western, Central, and Eastern Indonesia regions were represented by Padang Pariaman District, Manado City, and Kupang City. The design used in this study was the Rapid Assessment Procedure (RAP), a qualitative approach that was likely to be carried out quickly (around 1-2 months) regarding health-related behavior. ${ }^{10}$

In this study, the validity and reliability were examined through the triangulation of sources and methods. Triangulation was carried out to check the validity of the data. ${ }^{11}$ To establish credibility, the authors had well-established cooperation with the participants. The external key informant's reviews of the information were carried out, with additional comments also being used.

Data collection was carried out in two ways, namely focus group discussions (FGD) and in-depth interviews (IDI), through a semi-structured interview approach. The study instrument in the qualitative study was the author. The study instrument in the qualitative study was the author. Interviewers were equipped with semi- structured guidelines for the questions to be identified properly, both in FGDs and IDIs. These guidelines were used as a benchmark for interviewers to gather information from the informants. Despite the guidelines had been arranged in such a pattern, the interviewer was still provided with the freedom to explore and develop deep questions for the informants, as the objectives were achieved.

The total informants for IDI were 47 for the three locations (Padang Pariaman, Kupang, and Manado). The number of informants in Padang Pariaman was 20 for IDI, with two groups each consisting seven of respondents for FGD. However, in Kupang and Manado City, the total informants that participated for IDI were 12 and 13, with two groups each for FGD, respectively. Informants of the IDI were users of NHI-RHSs, particularly mothers and families (including young women), NHI administrative staffs at health facilities, clinical officers (midwives and doctors) as medical care providers, and officials related to the program (NHI) services. The program officials included the head of primary health care at the region medical office level and units related to NHI and their staffs.

All IDIs and FGDs were conducted, recorded, and transcribed verbatim. Furthermore, the data transcripts were cleaned initially by re-checking the suitability with the contents of the recordings on the audio recorder and field notes for data accuracy purposes. Afterwards the data were processed using NVivo version 2.0 software (license of the software is available). The purpose of using this software was to minimize subjectivity from the authors by looking at the data obtained in detail. ${ }^{12}$

Moreover, data analysis was carried out using thematic assessment to discover "patterns" that other parties were unable to observe clearly. ${ }^{13}$ Patterns or themes occurred randomly in the pile of available information. After finding a pattern, classification was conducted, by providing labels, definitions, or descriptions. ${ }^{14,15}$

\section{Results}

The participants of this study are summarized in Table 1. According to Table 1, the informants in this research based on RHSs utilization in health care facilities in the three provinces were both married women and the adolescent groups. For the stakeholders, the informants consisted of midwives, health care doctors, NHI administrators at clinical centers and hospitals, with the heads of medical district offices and National Health Insurance at the areas.

The two themes developed from eight sub-themes discovered in the study were briefly summarized in Table 2. The description of all the observations of knowledge was divided into four sub-themes.

Informant knowledge about RHSs covered by NHI had not been evenly distributed, especially among those from the community having inadequate awareness, compared to the health workers and administrative staff 
Table 1. Informants Groups Characteristics for In-Depth Interview and Focus Group Discussion

\begin{tabular}{lll}
\hline Informants Group & Position & Information Gather Method \\
\hline Married women & Ever use NHI & FGD \\
Married women & Never use NHI & FGD \\
Adolescent $(<18$ years old $)$ & Ever use NHI & FGD \\
Adolescent $(<18$ years old $)$ & Never use NHI & FGD \\
Family of woman/NHI user & Ever use NHI & IDI \\
Head of a health care center & NHI provider & IDI \\
NHI administration staff & NHI provider & IDI \\
Midwives/doctors at a health care center & NHI provider & IDI \\
Midwives/doctors at hospitals & NHI provider & IDI \\
Head of health office & NHI provider & IDI \\
Head of NHI at regent & NHI provider & IDI \\
NHI staff & NHI administration staff at hospitals & IDI \\
\hline
\end{tabular}

Notes: NHI = National Health Insurance, IDI $=$ in-depth interviews, FGD = Focus Group Discussion

Table 2 Theme, Sub-theme, and Relevant Quotations of In-Depth Interview and Focus Group Discussion

\begin{tabular}{|c|c|c|}
\hline Theme & Sub-theme & Quotations \\
\hline \multirow[t]{5}{*}{ Knowledge } & RHSs that are covered by NHI & $\begin{array}{l}\text { "... (I) do not know and have never heard about it...” (IDI, Adolescent - Kupang). } \\
\text { “.. I do not know..." (IDI, Adolescent - Padang Pariaman) }\end{array}$ \\
\hline & Types of HCSs that are covered by NHI & $\begin{array}{l}\text { "... pregnancy, childbirth, postpartum, contraception, STI, HIV \& AIDS, detection of cervical can- } \\
\text { cer, adolescent reproductive health..." (IDI, Woman - Padang Pariaman). } \\
\text { "... pregnant women, childbirth, family planning, adolescent reproductive health, STIs, early detect- } \\
\text { ion of cancer..." (IDI, Midwife at primary health care-Kupang) }\end{array}$ \\
\hline & Types of HCS that are not covered by NHI & $\begin{array}{l}\text { "... Abnormalities due to pathology. I don't think that procedure for transgender is covered..." } \\
\text { (Doctor at a hospital - Padang Pariaman). }\end{array}$ \\
\hline & & $\begin{array}{l}\text { "... all diseases, IVA and pap smear. Safe abortion need to be considered for NHI responsibility..." } \\
\text { (IDI, adolescent - Manado) }\end{array}$ \\
\hline & Sources of information on RHSs covered by NHI & "...colleagues. NHI prepares posters for us to post..." (Doctor at primary health care - Kupang) \\
\hline \multirow[t]{4}{*}{ Attitude } & $\begin{array}{l}\text { Towards improving the quality of reproductive } \\
\text { health }\end{array}$ & $\begin{array}{l}\text { "... Yes, I feel much better, Everything has been provided by NHI..." (Mother - Padang Pariaman) } \\
\text { "... Agree. Because as a teenager, we can have MCU for reproductive health issue earlier... " (IDI, } \\
\text { adolescent - Kupang) } \\
\text { "... both RHSs and surgery is very good, and it needs to be maintained... " (IDI, Adolescent - } \\
\text { Manado) }\end{array}$ \\
\hline & Towards access to NHI services & $\begin{array}{l}\text { "... it was easier when using in hospitals, clinics, and primary health care.” (IDI, Family used NHI - } \\
\text { Manado). } \\
\text { “... disagree. It is not complicated...” (IDI, Adolescent - Kupang) } \\
\text { “...no complicated at all...." (IDI, adolescent NHI user - Padang Pariaman) } \\
\text {... not really... as long as follow the procedure ...” (IDI, Housewive - Kupang) }\end{array}$ \\
\hline & Toward the fulfill of women's interests & $\begin{array}{l}\text { "... for reproductive health checkups, STIs, IVA, and rooms for adolescents are separate ..." (IDI, } \\
\text { Primary health care administrative staff - Kupang) }\end{array}$ \\
\hline & Towards NHI attention to RHSs & $\begin{array}{l}\text { "...I don't think so.. The services have paid attention to gender, only the information that has not } \\
\text { been widely spread, yet." (IDI, Mother - Kupang) } \\
\text { "... Disagree. For example, for women that continues sterilization contraceptives after delivery, the } \\
\text { insurance is likely to still be claimed after } 40 \text { days...." (IDI, Doctor's Hospital - Kupang) } \\
\text { "... if the patient is admitted as an NHI patient, then the service seems slow... " (FGD- Kupang) }\end{array}$ \\
\hline
\end{tabular}

Notes: RHSs $=$ Reproductive Health Services, HCS $=$ Health Care Service, NHI $=$ National Health Insurance, IDI $=$ in-depth interviews, FGD $=$ Focus Group Discussion, MCU = Medical Check Up, IVA = Inspeksi Visual Asetat, STIs = Sexually Transmitted Infections

of NHI.

"... (I) do not know and have never heard about it...

(IDI, Adolescent - Kupang).

Most informants knew the types of health care covered by NHI, as they mentioned them more. However, there were also respondents with limited knowledge of the treatment of severe diseases, such as cancer and cesarean section. Also, health worker informants were able to explain medical care covered by NHI.

According to informants, NHI types that are not covered by NHI were fertility issues (IVF), costs for transgender, and safe abortion surgeries. Health worker informants believed that safe abortion should be considered and covered by the NHI.

Most information about RHSs covered by NHI were known from family and relatives that work in health institutions. Medical informants made it known that there was an involvement of various parties in the dissemination of information, which was related to RHSs for women included in the NHI scheme. 
"... colleagues that deliver. NHI prepares posters for us to post to the public.... " (IDI, Doctor at primary health care - Kupang)

The Attitude's sub-theme was viewed from several aspects, including Quality of RHSs, Access to NHI Services, Health Services that Fulfill Women's Interests, and NHI Attention to RHSs. Some informants agreed with the statement that the quality of RHSs covered by NHI was improved. A housewife respondent in Padang Pariaman that had used NHI, provided information about never buying drugs because all was provided, and the flow had been regulated through the NHI scheme.

"... Yes, I feel much better; everything has been provided

by NHI... "(IDI, Mother - Padang Pariaman)

One adolescent informant in Kupang City also provided information that the inclusion of RHSs in the NHI scheme had led to an increase in the quality of HCSs, through the access of obtaining it (RHSs) for women.

"...Agree. Because as a teenager we can have MCU for reproductive health issue earlier..." (Adolescent Kupang)

Although there were relatively many informants that agreed that the quality of health care services (HCSs) covered by NHI was getting better, some also expressed their need to improve the efficiency of the services.

Informants' attitudes were explored through the statement, "Access to get NHI services is complicated and 'convoluted'. Some expressed their disagreement with the statement, as they believed that NHI participants obtain priority, through the experience of using the services.

"... Based on my experience while using NHI, it is very

easy and hassle-free, especially when using it in

hospitals and clinics, with primary health care..." (IDI,

Family used NHI - Manado)

The informants' attitude to the statement, "the services provided by NHI still apply in general, and do not pay attention to the specific interests of women or men", was not fully agreed upon by the health officer respondents. According to them, in terms of facilities, there were already separate rooms for female and male patients to conduct reproductive health checkups and other actions, such as sexually transmitted infection (STI) management and inspeksi visual asetat (IVA).

"... for reproductive health checkups, for STIs and IVA,

rooms for adolescents, all are separate ... " (IDI, primary

health care administrative staff - Kupang)

This statement was in line with the opinion of adolescent informants in Kupang, which stated that there were separate rooms designated for adolescents, which functioned as a zone for counseling on reproductive health. However, this condition was not observed in all regions. In Padang Pariaman, for example, due to the limitations of existing facilities, the separation between examination rooms or inspection procedures according to gender was sometimes not yet fulfilled. This situation was also acknowledged by a doctor informant at a hospital in Kupang City.

"...Agree. For 3rd class, it is unavailable, because there are around 6 to 7 people in one ward. Even though there are curtains between the beds, it is not really closed to ensure privacy..." (IDI, Doctor at a hospital - Kupang)

One informant from Kupang further stated that the problem was the lack of dissemination of information on RHSs, for women and adolescents. This was the reason many people still thought there was no separation of RHSs, which was general in nature.

"I think no, the service has paid attention to the interests of women or men, only the information has not been widely spread." (Mother- Kupang)

Regarding the attitude to the statement "Womanrelated RHSs has become the concern of the NHI", several service users and health workers as informants from both Manado and Kupang Cities, believed that the NHI had provided more attention to services related to reproductive health. One of them was the promotive roles in communication or counseling regarding both the functional and procedural management of NHI and HCS, which was included in the National Health Insurance financing scheme. In this promotive activity, NHI was usually accompanied by the local health services, through the availability of RHSs for early examinations, which were related to the reproductive organs and management, or care associated to ANC and post-partum. It was evidenced that the NHI had provided attention to women-specific reproductive health.

"... Right, it's not that... there are already services for mothers giving birth... Abnormal menstruation can be served by NHI..." (IDI, Adolescent -Padang Pariaman)

Although many informants had stated their agreement, some did not agree that woman-related RHSs had become the concern of the NHI. The respondents that disagreed were health workers in Kupang and Padang Pariaman.

"... Disagree because, for example, for women that deliver and immediately take sterilization contraceptives, the insurance is likely to be still claimed but if after two weeks (heading to) sterile unclaimed. Except after 40 days it can only be claimed... " (IDI, Doctor's Hospital - Kupang)

The types of RHSs utilized by informants were relatively varied. These services included examining the reproductive organs, pregnancy checkups, and assistance in the form of medical interventions, such as normal delivery, cesarean section, and removal of the myoma.

"... more than five years I have been using NHI cards.

It was often used for regular medical treatment and 
most recently for cesarean delivery ..." (FGD - Kupang)

Practically, the community had barriers in using NHI membership to obtain RHSs. The barriers were divided into two, namely internal and external barriers, originating from within and outside the individual.

Aspects from within the informant that hindered the use of RHSs, was a culture of shame and fear of reproductive health checkups. In some areas, discussing reproductive-related problems was still considered a taboo. Therefore, there was a reluctance to have a reproductive health checkup.

"...From women themselves, for example, a culture of shame and fear. Don't let it be examined by a male doctor, embarrassed about revealing personal matter, embarrassed when you have to take off your clothes while checking up, getting scared to know if there is an illness...” (IDI, Doctor at primary health care - Kupang)

Lack of knowledge about RHSs was also one of the barriers to the use of RHSs. External barriers included the costs incurred despite using NHI cards to get services. Some medicines were not covered by the insurance program, therefore ensuring patients pay outof-pocket.

"... Medicines above IDR 30,000 are paid by NHI, but patients themselves redeem the medicines above IDR 50,000 ..." (FGD - Kupang)

The slow handling of NHI participant patients also made the informants reluctant to use cards for treatment. Conversely, general patients that pay out-of-pocket tended to get services and treatment immediately. Furthermore, one of the heads of primary health care in Manado City stated that being busy with work and household activities that could not be left behind, caused the loss of time to have reproductive health checkups.

"... What hampers women's access to the NHI was more

to themselves, due to being busy with work and other

activities ..." (IDI, Head of primary health care -

Manado)

The family also played a role in women's access to RHSs. In some cases, the husband had a role in deciding on contraceptives for the wife. The husband and family also played an important role in determining where pregnant women were to deliver.

"... Lack of sex education. However, some women also came, but for contraception, it is still the husband that plays an important role even though we have explained it, or they already have many children..." (IDI, Doctor at a hospital - Kupang)

\section{Discussion}

Health insurance played a role in healthcare access and service utilization. ${ }^{16}$ Information, education, and communication campaigns were necessary to enhance the utilization of health insurance coverage. ${ }^{17}$ Based on the results obtained from a study conducted by Kurfi, ${ }^{18}$ general knowledge of the NHI scheme had a positive and significant relationship with client's satisfaction. The results of this study indicated that informants' knowledge of RHSs covered by NHI, had not been evenly distributed. Knowledges of the health workers and administrative officers were better than the community respondents. Some community informants knew that the RHSs covered by NHI were pregnancy checkups, postpartum examinations, early detection of cancer, family planning services, and other diseases related to reproductive organs. Health services that were not covered by NHI included treatment for infertility, sex reassignment procedure for transgender, and safe abortion (medical abortion), in cases of pregnancy complications. A study by Oyenike, et al., ${ }^{19}$ showed a significant influence of knowledge $\left(\mathrm{R}^{2}=0.683\right.$, $\mathrm{p}$-value $\left.=0.000\right)$ on the utilization of the NHI scheme. ${ }^{19}$ Effective strategies should be implemented towards increasing awareness and knowledge about health insurance. ${ }^{20}$

The information on RHSs covered by NHI, was generally obtained from the closest people, health workers, and medical insurance officers. Furthermore, visual media such as posters were also displayed at health facilities. One of the factors associated with low access to RHSs with the NHI scheme was the low knowledge and awareness about the availability of the program.9,21 Lack of knowledge on health insurance, particularly about coverage on preventive care, also led consumers to avoid assistance due to perceived costs. ${ }^{22}$ In conveying the information, visual media had to be accompanied by direct information from the person concerned, for data to be comprehensively received in more detail. In a study by Yakong, et al., 23 the community needs for family planning information were not met. Though the Family Planning posters were displayed at health facilities, they did not significantly impact due to the lack of education or illiteracy.

Lack of knowledge about HCS also led to the underutilization of health services. A study among Thai immigrants by Akerman, et al., ${ }^{24}$ showed that $52 \%$ of respondents were not aware of the location to seek RHSs, due to the lack of information. To increase knowledge, applications through various platforms and technologies should be available to the community, such as mass or social media. In a previous study, expanding understanding of RHSs, especially among adolescents, showed a significant relationship between knowledge and exposure to the mass media. 25

The attitude is a psychological tendency expressed by evaluating certain entities with several levels, for example, agree or disagree. ${ }^{26}$ Attitude was useful in predicting behavior, when it is not considered a problem by the per- 
son. This was accompanied by social acceptance of actions, which were in line with the person's attitude. ${ }^{27}$ Some informants had positive attitudes, which improved the quality of health services for NHI participants. Generally, the explanations cited for considering the improved quality were the ease of locating medicines because they had been determined. Furthermore, the involvement of reproductive health in the services covered by NHI, also made it easier for the public to access RHSs.

Although RHSs were available in the community, the utilization remained low due to the perceived negative attitude from the health workers, lack of privacy, and social norms. ${ }^{28}$ A study conducted by Adjei, ${ }^{29}$ in Ghana, showed that health insurance beneficiaries had high trust in their primary care provider by giving them quality assistance. However, in this study, the negative attitude shown by the informants was due to dissatisfaction with the services from health workers that seemed to discriminate between patients that pay out-of-pocket and NHI participants. Also, a negative attitude was shown in the statement on access to obtain NHI services, which were complicated and 'convoluted'. This meant that informants considered that the pathway to be followed by NHI participants to receive health services was not complicated. Complicating matters were when the administrative requirements were incomplete. A study by Campbell, et al., 30 among the artisans, showed that an insufficient level of knowledge and awareness of health insurance translated to a negative attitude towards the scheme. There was a need for a substantial stakeholders' enlightenment campaign to increase coverage.

Additionally, some informants disagreed with the statement that the services provided under NHI did not pay attention to the specific interests of women or men. According to the health worker informants, there was already room partitioning to perform actions, such as STIs management and IVA. Even when there were barriers, it was due to the inequality of facilities and infrastructure at health structures. Lack of attention to patients' privacy, especially in RHSs, played a role in using health facilities. ${ }^{21,31}$ A study by Adetona, et al., ${ }^{19}$ showed a significant influence of attitude $\left(\mathrm{R}^{2}=0.872\right.$, p-value $\left.=0.000\right)$ on the utilization of the NHI scheme. Informants in this study agreed to the women's RHSs had become the concern of the NHI. This utilization was indicated the counseling on the functions and procedures for managing $\mathrm{NHI}$, including RHS as one of the services covered by the insurance scheme. In the Regulation of BPJS No. 1 of 2014, the scope of NHI services included promotive services and preventive care. ${ }^{32}$ However, informants that disagreed expressed that they still felt the facilities and infrastructure for RHSs had not been optimal.

The types of RHSs used by informants were relatively varied. These services included examining reproductive organs, pregnancy examinations, and services in the form of medical interventions, such as normal delivery, cesarean section, and removal of myoma. The factor that encouraged informants to use RHSs using NHI, was the cost relief (free of charge) offered to register participants.

The barriers shown by the informants were divided into internal and external barriers. The internal barriers included lack of knowledge about RHSs covered by NHI, therefore allowing informants feel uncertain about using health services covered by the insurance scheme. Also, there was still a culture of shame for informants, as they were reluctant to have checkups at the health facility. Shyness was influenced by the values prevailing in the society, for example, religion. The norms and characteristics of some religious groups encouraged negative attitudes to medical matters. These facts are shown by the studies of Gyimah, ${ }^{33}$ Tlaye, ${ }^{25}$ Ansha, ${ }^{31}$, and Negash, ${ }^{21}$ which stated that shame and fear of some social values made respondents reluctant to access RHSs, unlike those that were already sexually active.

Conversely, external barriers that made people reluctant to use NHI for health checkups included the additional costs incurred because some medicines were not covered by the insurance scheme. This observation indicated that affordability was still an obstacle, even for the insured informants, to utilize health services and join the NHI scheme. This was in line with the results from studies by Gobah, ${ }^{34}$ and Mensah, ${ }^{35}$ which showed that difficulties in affording the cost of health care, were one of the major obstacles to the enrollment of the NHI scheme.

Besides that, dissatisfaction with health services provided by health workers also made informants reluctant to use NHI. Informants argued that non-NHI patients were prioritized and treated faster than those insured. Similar to existing studies, most of the insured patients perceived and experienced long waiting times, verbal abuse, not being physically examined, and discrimination in favor of the affluent and uninsured. 36 Patient satisfaction influenced the decision in selecting a health facility as a place of treatment. A study by Gan-Yadam, et al.,37 in Mongolia, showed that patients that were satisfied with the services at the health facilities were more likely to select the same medical infrastructure repetitively. The study by Yakong, et al., ${ }^{23}$ also showed that dissatisfaction with the services by health workers had a role in the choice of treatment. In this study, patients were not only wanted to be treated, they were also accompanied by clear information to address the health problems being encountered. The government should further adjust NHI schemes and optimize the allocation of health resources to alleviate the inequality across policies and enhance the effective utilization of medical care services. 38

In this study, busy work and household chores also made informants lose time for a reproductive health 
checkups. Inconvenient service hours remained a considerable reason for respondents not utilizing reproductive health services. ${ }^{21}$ Concerning health insurance, encouragement by friends and family was observed to motivate subscription to health insurance. ${ }^{39}$ For example, the husband had a role in determining contraceptives for the wife, or in determining the location for pregnant women to deliver. In reproductive health, women's autonomy was an important socio-cultural factor, which played a role in using of health facilities. ${ }^{40}$ This study, consistent with other results, showed that the husband had a role in making decisions in the family, and that women's autonomy in decision-making was very limited, including the basis of the female reproductive health. ${ }^{41,42}$ Husbands as the head of households should be motivated by health practitioners on the utilization of the National Health Insurance scheme, as this ensured the achievement of universal medical coverage. ${ }^{19}$ These results further indicated the need for demand-side intervention among enrolled families to maximize the government's efforts in increasing access to health services.

The researchers observed some weaknesses in this study, such as locating informants, which was in line with the inclusion criterion. Thematic analysis in this study had limited the formation of themes based on information provided by informants. Another weakness was the different interviewers for every three locations, which in turn became an obstacle in data analysis. However, the researchers discovered numerous information that should be investigated further, through quantitative research for a huge population, such as knowledge about types of RHSs covered by NHI or about the health insurance itself. Alongside good coordination with the counterpart in three different provinces, this study had a pattern of reproductive health services by NHI, which should be shared as a recommendation to the government, as a continuous improvement.

\section{Conclusion}

Informants' knowledge towards reproductive health and RHSs covered by NHI varied. Some informants have the knowledge about the type of services covered by the $\mathrm{NHI}$, as others from the youth and maternal groups were still unaware. Albeit the dissemination of NHI information and what RHSs covered was all about, more equitable distribution was needed by health workers or NHI staff, as information was to be delivered accurately to the community.

Generally, informants had a good assessment of NHI and RHSs, and also a positive attitude to improve the programs. Community informants and health workers also had a positive attitude toward women RHSs by NHI. However, most informants disagreed with the statement that access to get NHI services is complicated. Also, most informants agreed with NHI services nowadays in terms of considering gender.

Internal barriers in the use of NHI for RHSs also showed a culture of shame and fear of being examined, with lack of information. External barriers felt by informants included works and household activities, with inadequacy of women's participation in family decisionmaking, including reproductive health issues. Other barriers were dissatisfaction with the services provided by health workers, and additional costs for medicines not covered by NHI.

\begin{abstract}
Abbreviations
BPJS: Badan Penyelenggara Jaminan Sosial; NHI: National Health Insurance; IDI: In-Depth Interview; RHS: Reproductive Health Services; FGD: Focus Group Discussion; ICPD: The International Conference on Population and Development; HCS: Health Care Service; SRHR: Sexual and Reproductive Health and Rights; SDG: Sustainable Development Goal; STI: Sexually Transmitted Infection; IVA: Inspeksi Visual Asetat.
\end{abstract}

\section{Ethics Approval and Consent to Participate}

This study was conducted after ethical approval was obtained from Institutional Review Board at the University of Indonesia, with numbers LB.02.01/2/KE.296/2018. Moreover, before data collection, informed consent had been provided by all the informants and key respondents in the three provinces.

\section{Competing Interest}

The authors declare declared that there are no significant competing financial, professional, or personal interests that was likely to have affected the performance or presentation of the work described in this manuscript.

\section{Availability of Data and Materials}

Data was available from the corresponding author on request.

\section{Authors' Contribution}

EM and HL conceived the proposal of the study, data collection, and analysis. EM also wrote the initial draft of the manuscript. RSZ studied literature, data analysis, and wrote the initial draft of the manuscript. YS re-analyzed data, updated the literature, and made the improvement of the final manuscript.

\section{Acknowledgment}

The authors were grateful to all participants of NHI user and MAMPUAUSAID as regards funding. They are also grateful to Yayasan Kesehatan Perempuan, PIAR NTT in Kupang City, Swara Parangpuan Manado, LP2M in Padang District, and Jaringan Perempuan Peduli Kesehatan, for generously collaborating, in order to perform this study.

\section{References}

1. United Nations General Assembly. Principle 1 and principle 4, respectively, of the ICPD programme of action, uphold human rights 
and gender equality and equity and women's empowerment. In: Report of the International Conference on Population and Development A/94/10/18 Programme of Action. New York: United Nations. 1995. p. 11-2.

2. Plesons M, Cole CB, Hainsworth G, Avila R, Va Eceéce Biaukula K, Husain S, et al. Forward, together: a collaborative path to comprehensive adolescent sexual and reproductive health and rights in our time. Journal of Adolescent Health. 2019; 65 (6): S51-62.

3. Ravindran TKS, Govender V. Sexual and reproductive health services in universal health coverage: a review of recent evidence from lowand middle-income countries. Sex Reprod Heal Matters. 2020; 28 (2).

4. Kieny MP, Evans DB. Universal health coverage. Eastern Mediterranean Health Journal. 2013; 19 (4): 305-6.

5. Hasstedt K, Desai S, Ansari-Thomas Z. Immigrant women's access to sexual and reproductive health coverage and care in the United States. Issue Brief (Commonw Fund). 2018. p. 1-10.

6. Yayasan Kesehatan Perempuan. Laporan studi pelaksanaan skema jaminan kesehatan nasional (JKN) dalam kaitannya dengan kebutuhan perempuan dan pelayanan kesehatan reproduksi dan seksual; 2017.

7. Peters SAE, Woodward M, Jha V, Kennedy S, Norton R. Women's health: a new global agenda. BMJ Global Health. 2016; 1 (3): 1-8.

8. Manze MG, Romero DR, Sumberg A, Gagnon M, Roberts L, Jones H. Women's perspectives on reproductive health services in primary care. Family Medicine. 2020; 52 (2): 112-9.

9. Mozumdar A, Aruldas K, Jain A, Reichenbach L. Understanding the use of India's national health insurance scheme for family planning and reproductive health services in Uttar Pradesh. International Journal of Health Planning and Management. 2018; 33 (4): 823-35.

10. Scrimshaw Nevin S and Gleason Gary R. Rapid assessment procedures: qualitative methodologies for planning and evaluation of health related programmes (international nutrition foundation for developing countries- INFDC). Scrimshaw Nevin S and Gleason Gary R., editor. Boston, Ma.: Library of Congress Cataloging-in-PublicationData. 1996. p. 588.

11. Din N. Manajemen penerapan perilaku hidup bersih dan sehat (PHBS) tatanan rumah tangga di Kelurahan Kurao Pagang Kota Padang tahun 2016. J Endur. 2016; 1.

12. Zamawe FC. The implication of using NVivo software in qualitative data analysis: evidence-based reflections. Malawi Medical Journal. 2015; 27 (1): 13-5.

13. Nowell LS, Norris JM, White DE, Moules NJ. Thematic analysis: striving to meet the trustworthiness criteria. International Journal of Qualitative Methods. 2017; 16 (1): 1-13.

14. Boyatzis RE. Transforming qualitative information: thematic analysis and code development. Thousand Oaks, California: Sage Publications, Inc.; 1998.

15. Stuckey H. The second step in data analysis: coding qualitative research data. Journal of Social Health and Diabetes. 2015; 03 (01): 007-10.

16. Allcock SH, Young EH, Sandhu MS. Sociodemographic patterns of health insurance coverage in Namibia. International Journal for Equity in Health. 2019; 18 (1): 1-11.

17. Nguyen TD, Wilson A. Coverage of health insurance among the nearpoor in rural Vietnam and associated factors. International Journal of
Public Health. 2017; 62 (s1): 63-73.

18. Mustapha Kurfi M, Hussaini Aliero I, Author C. A study on clients' satisfaction on the national health insurance scheme among staff of Usmanu Danfodiyo University Sokoto. IOSR Journal of Economics and Finance. 2017; 8 (5): 44-52.

19. Adetona TO, Kio JO. Determinants of national health insurance scheme utilization among heads of households in selected communities in Ogun State, Nigeria. International Journal of Academic Research in Business, Arts \& Science. 2020; 7354: 142-54.

20. Yusuf HO, Kanma-Okafor OJ, Ladi-Akinyemi TW, Eze UT, Egwuonwu CC, Osibogun AO. Health insurance knowledge, attitude and the uptake of community-based health insurance scheme among residents of a suburb in Lagos, Nigeria. West African Journal of Medicine. 2019; 36 (2): 103-11.

21. Negash W, Dessalegn M, Yitayew B, Demsie M, Wagnew M, Nyagero J. Reproductive health service utilization and associated factors: the case of North Shewa zone youth, Amhara region, Ethiopia. Pan African Medical Journal. 2016; 25 (Supp 2): 3.

22. Smith KT, Monti D, Mir N, Peters E, Tipirneni R, Politi MC. Access is necessary but not sufficient: factors influencing delay and avoidance of health care services. MDM Policy \& Practice. 2018; 3(1): 238146831876029.

23. Yakong VN, Rush KL, Bassett-Smith J, Bottorff JL, Robinson C. Women's experiences of seeking reproductive health care in rural Ghana: challenges for maternal health service utilization. Journal of Advanced Nursing. 2010; 66 (11): 2431-41.

24. Åkerman E, Östergren P, Essén B, Fernbrant C, Westerling R. Knowledge and utilization of sexual and reproductive healthcare services among Thai immigrant women in Sweden. BMC International Health and Human Rights. 2016; 1-14.

25. Tlaye KG, Belete MA, Demelew TM, Getu MA, Astawesegn FH. Reproductive health services utilization and its associated factors among adolescents in Debre Berhan town, Central Ethiopia: a community-based cross-sectional study. Reprod Health. 2018; 15 (1): $1-11$.

26. Schwarz N, Bohner G. The Construction of attitudes. Blackwell Handbook of Social Psychology; 2001.

27. Chaiklin H. Attitudes, behavior, and social practice. The Journal of Sociology and \& Social Welfare. 2011; 38 (1).

28. Kyilleh JM, Tabong PTN, Konlaan BB. Adolescents' reproductive health knowledge, choices and factors affecting reproductive health choices: a qualitative study in the West Gonja District in Northern region, Ghana. BMC International Health and Human Rights. 2018; 18 (1): $1-12$.

29. Andoh-Adjei FX, Cornelissen D, Asante FA, Spaan E, Van Der Velden K. Does capitation payment under national health insurance affect subscribers' trust in their primary care provider? a cross-sectional survey of insurance subscribers in Ghana. BMC Health Services Research. 2016; 16 (1): 1-10.

30. Campbell P, Owoka O, Odugbemi T. National health insurance scheme: are the artisans benefitting in Lagos state, Nigeria? Journal of Clinical Sciences. 2016; 13( 3): 122.

31. Ansha MG, Bosho CJ, Jaleta FT. Reproductive health services utilization and associated factors among adolescents in Anchar 
District, East Ethiopia. Journal of Family \& Reproductive Health. 2017; 11 (2): 110-8.

32. Badan Penyelenggara Jaminan Sosial Kesehatan. Peraturan Badan Penyelenggara Jaminan Sosial Kesehatan Nomor 1 tahun 2014 tentang penyelenggaraan jaminan kesehatan. Jakarta; 2013.

33. Gyimah SO, Takyi BK, Addai I. Challenges to the reproductive-health needs of African women: on religion and maternal health utilization in Ghana. Social Science \& Medicine. 2006; 62 (12): 2930-44.

34. Gobah FK, Zhang L. The national health insurance scheme in Ghana: prospects and challenges: a cross-sectional evidence. Global Journal of Health Science. 2011; 3 (2): 90-101.

35. Mensah J, Oppong JR, Schmidt CM. Ghana's national health insurance scheme in the context of the health MDGs: an empirical evaluation using propensity score matching. Health Economics. 2010; 19 (Suppl. 1): 95-106.

36. Dalinjong PA, Laar AS. The national health insurance scheme: perceptions and experiences of health care providers and clients in two districts of Ghana. Health Econ Rev. 2012; 2 (1): 1-13.

37. Gan-Yadam A, Shinohara R, Sugisawa Y, Tanaka E, Watanabe T, Hirano M, et al. Factors associated with health service utilization in Ulaanbaatar, Mongolia: a population-based survey. Journal of
Epidemiology. 2013; 23 (5): 320-8.

38. Wang Z, Li X, Chen M, Si L. Social health insurance, healthcare utilization, and costs in middle-aged and elderly community-dwelling adults in China. International Journal for Equity in Health. 2018; 17 (1): $1-13$.

39. Kumi-Kyereme A, Amu H, Darteh EKM. Barriers and motivations for health insurance subscription in Cape Coast, Ghana: a qualitative study. ARC Journal of Public Health and Community Medicine. 2017; 75 (1): 1-10.

40. Haque SE, Rahman M, Mostofa MG, Zahan MS. Reproductive health care utilization among young mothers in Bangladesh: does autonomy matter?. Women's Health Issues. 2012; 22 (2): e171-80.

41. Ganle JK, Obeng B, Segbefia AY, Mwinyuri V, Yeboah JY, Baatiema L. How intra-familial decision-making affects women's access to, and use of maternal healthcare services in Ghana: a qualitative study. BMC Pregnancy Childbirth. 2015; 15 (1): 1-17.

42. Jalu MT, Ahmed A, Hashi A, Tekilu A. Exploring barriers to reproductive, maternal, child and neonatal $(\mathrm{RMNCH})$ health-seeking behaviors in Somali region, Ethiopia. PLoS One. 2019; 14 (3): 1-15. 